\title{
Enhanced gravity-wave activity and interhemispheric coupling during the MaCWAVE/MIDAS northern summer program 2002
}

\author{
E. Becker ${ }^{1}$ and D. C. Fritts ${ }^{2}$ \\ ${ }^{1}$ Leibniz-Institute of Atmospheric Physics, Kühlungsborn, Germany \\ ${ }^{2}$ Colorado Research Associates Division, Northwest Research Associates, Boulder, Colorado, USA
}

Received: 19 July 2005 - Revised: 2 February 2006 - Accepted: 13 Febraury 2006 - Published: 3 July 2006

Part of Special Issue "MaCWAVE: a rocket-lidar-radar program to study the polar mesosphere during summer and winter"

\begin{abstract}
We present new sensitivity experiments that link observed anomalies of the mesosphere and lower thermosphere at high latitudes during the MaCWAVE/MIDAS summer program 2002 to enhanced planetary Rossby-wave activity in the austral winter troposphere.
\end{abstract}

We employ the same general concept of a GCM having simplified representations of radiative and latent heating as in a previous study by Becker et al. (2004). In the present version, however, the model includes no gravity wave (GW) parameterization. Instead we employ a high vertical and a moderate horizontal resolution in order to describe GW effects explicitly. This is supported by advanced, nonlinear momentum diffusion schemes that allow for a self-consistent generation of inertia and mid-frequency GWs in the lower atmosphere, their vertical propagation into the mesosphere and lower thermosphere, and their subsequent dissipation which is induced by prescribed horizontal and vertical mixing lengths as functions of height.

The main anomalies in northern summer 2002 consist of higher temperatures than usual above $82 \mathrm{~km}$, an anomalous eastward mean zonal wind between 70 and $90 \mathrm{~km}$, an altered meridional flow, enhanced turbulent dissipation below $80 \mathrm{~km}$, and enhanced temperature variations associated with GWs. These signals are all reasonably described by differences between two long-integration perpetual model runs, one with normal July conditions, and another run with modified latent heating in the tropics and Southern Hemisphere to mimic conditions that correspond to the unusual austral winter 2002. The model response to the enhanced winter hemisphere Rossby-wave activity has resulted in both an interhemispheric coupling through a downward shift of the GW-driven branch of the residual circulation and an increased GW activity at high summer latitudes. Thus a quantitative explanation of the dynamical state of the

Correspondence to: E. Becker

(becker@iap-kborn.de) northern mesosphere and lower thermosphere during JuneAugust 2002 requires an enhanced Lorenz energy cycle and correspondingly enhanced GW sources in the troposphere, which in the model show up in both hemispheres.

Keywords. Meteorology and atmospheric dynamics (General circulation; Middle atmosphere dynamics; Waves and tides)

\section{Introduction}

The austral winter 2002 was an exceptional season in several respects. The most prominent feature was a major stratospheric warming observed above Antarctica in mid September - the first ever recorded in the southern winter hemisphere (Roscoe et al., 2005). This spectacular event triggered numerous investigations intended to identify its dynamical origin, which lies in the preceding temporal evolution of planetary Rossby waves (Harnik et al., 2005). Indeed, when considering the variability of the southern troposphere and stratosphere between June and September 2002, it is apparent that the entire season exhibited unusually strong planetary Rossby-wave activity (e.g. Baldwin et al., 2003). As a result, the southern polar night jet in 2002 was on average weaker, warmer, and more variable than in other years, to some extent resembling its boreal winter counterpart. Also the rather weak ozone hole in early spring 2002 can be attributed to the anomalous dynamics and the late winter major warming (Stolarski et al., 2005).

Coincidently, the MaCWAVE/MIDAS program to study the polar summer middle atmosphere took place in 2002 at the site of Andøya $\left(69.3^{\circ} \mathrm{N}\right.$ in northern Norway), performing observations of GWs, turbulence, and the mean dynamical state (Goldberg et al., 2004). Particular emphasis was placed on the upper mesosphere and lower thermosphere (MLT). In comparing the observations from 2002 with

Published by Copernicus GmbH on behalf of the European Geosciences Union. 

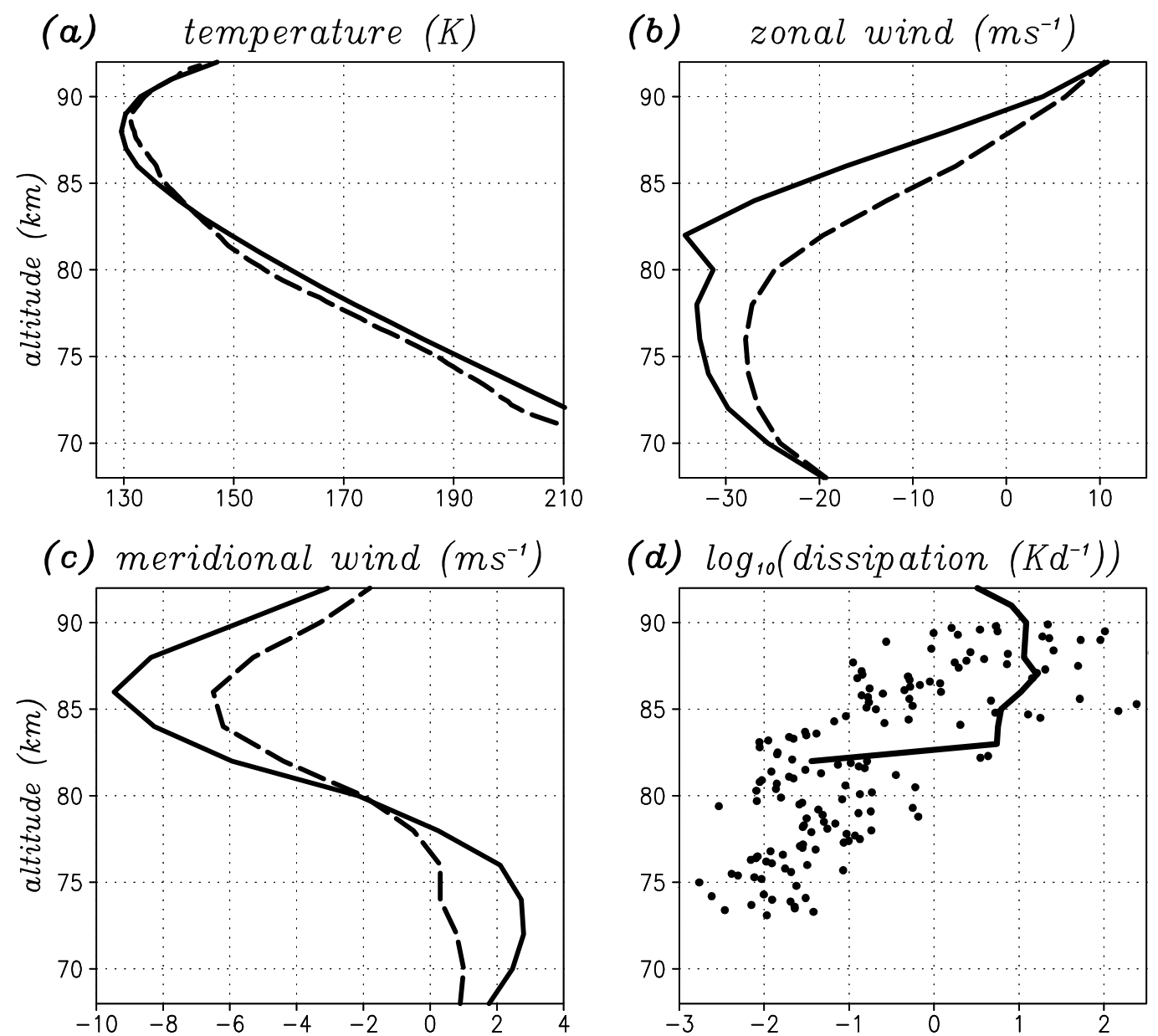

Fig. 1. The mean thermal and dynamical structure of the summer MLT at Andøya in years prior to 2002 (solid curves) and during the MaCWAVE/MIDAS campaign 2002 (dashed curves or dots). (a) Temperature based on falling sphere soundings. (b), (c) Mean horizontal winds obtained with the ALOMAR MF radar. (d) Turbulence dissipation rates based on CONE rocket soundings. For details of the different data sets see Goldberg et al. (2004), Singer et al. (2005), and Rapp et al. (2004).

those from previous years, systematic anomalies were identified. Figure 1 provides an overview of the major departures noted by Goldberg et al. (2004), Singer et al. (2005), Fritts et al. (2004), and Rapp et al. (2004). From panel (a) we see that the northern summer mesosphere in 2002 was colder than usual by $\sim 5 \mathrm{~K}$ below about $82 \mathrm{~km}$ and warmer at higher altitudes (see also Singer et al., 2005, Fig. 2). The observed mean zonal wind was also different from previous years, showing an anomalous eastward component between 70 and $90 \mathrm{~km}$ (Fig. 1b). An even more striking signal can be seen in the averaged radar observations of the meridional wind above Andøya (Fig. 1c). Since standing planetary waves are absent in the extratropical summer middle atmosphere according to the Charney-Drazin criterion (see Andrews et al., 1987), we expect the temporal mean temperature and zonal and meridional winds to be good approximations to the temporal zonal means. Therefore, the reduction and downward shift of the equatorward flow in Fig. 1c reflects a corresponding shift of the zonal-mean drag generated by the breakdown of internal GWs. Assuming that the turbulence in the MLT results primarily from the nonconservative propagation of GWs, the downward shift in the meridional wind should be associated with enhanced turbulence at lower altitudes than usual. Indeed, Rapp et al. (2004) observed significant turbulence dissipation rates as low as $73 \mathrm{~km}$ during the MaCWAVE/MIDAS northern summer program, whereas in previous summers turbulence had never been observed below $80 \mathrm{~km}$ (Lübken et al., 2002). The average dissipation rate prior to 2002 is depicted in Fig. 1d (solid curve) along with the individual soundings from 2002 (dots).

In an earlier study by Becker et al. (2004, B04) an attempt was made to relate these exceptional observations in the northern MLT during June-August 2002 to the anomalously high planetary Rossby-wave activity in the Southern Hemisphere at the same time. Those authors used a mechanistic GCM from the surface to $100 \mathrm{~km}$ providing explicit 
description of planetary and synoptic waves. However, GWs were parameterized according to Lindzen (1981) and Becker (2004), assuming a fixed, horizontally uniform GW source at $170 \mathrm{hPa}$. The mechanistic character of the model was due to its thermal forcing, using temperature relaxation to mimic radiative heating, prescribed tropical heating to represent the cumulus convection zones along the equator, and selfinduced condensational heating in middle latitudes (Körnich et al., 2003). The strength of this simplicity lies in the possibility to adjust the latent heating functions in order to realize different states of planetary Rossby-wave activity in perpetual long-integration simulations.

Taking advantage of this utility, B04 performed two simulations, one with "normal July" conditions and a sensitivity experiment with "July 2002" conditions. The general conclusion drawn by comparing the climatologies of both runs was that the aforementioned anomalous observations in the northern summer MLT can qualitatively be interpreted as the interhemispheric coupling communicated by a downward shift of the GW-driven summer-to-winter-pole residual circulation. In particular, enhanced Rossby-wave activity in the winter stratosphere leads to a weaker and more variable polar night jet, which in turn causes the saturation levels of GWs to shift to lower altitudes and to be distributed over a deeper height range (Becker and Schmitz, 2003). The associated weakening and downward shift of the GW-driven branch of the residual circulation in the winter hemisphere is accompanied by a corresponding shift in summer. This shift in summer can only exist in climatological equilibrium if the GW drag shifts downward as well, requiring enhanced eastward flow in the MLT, as observed (Fig. 1b). The associated temperature signal is also consistent with this argument, since a downward shift in GW drag implies enhanced adiabatic cooling in the lower part of the MLT and reduced adiabatic cooling above. Here we have ignored the direct thermodynamic effects associated with GW breakdown, which in the GW parameterization used in B04 were dominated by vertical mixing of entropy, causing strong cooling in the MLT and weak heating below the breaking levels (Becker, 2004). Hence the response of the direct thermodynamic effects to a downward shift in GW saturation added to the anomalous adiabatic heating. This interpretation by B04 applies at most qualitatively to the anomalous observations in the northern summer MLT during the MaCWAVE/MIDAS campaign.

There are, of course, many obvious reasons why one should not expect any quantitative agreement between the observations and mechanistic model estimates. For example, statistical significance tests for the differences in the observed dissipation rates are not possible due to the small amount of data. Also, the differences in the temperature profiles were obtained from only a limited number of soundings during 2002, leaving room for uncertainties. On the other hand, the SABER temperature retrievals reported by Goldberg et al. (2006) confirm lower temperatures than usual below $80 \mathrm{~km}$ for northern summer 2002 when compared to
2003 or 2004, and they support higher temperatures farther above for at least the difference between the 2002 and 2003 northern summer seasons. Furthermore, the more nearly continuous radar measurements of meridional and zonal winds may be considered to be robust.

Concerning the model, the simplistic thermal forcing is questionable with regard to both the troposphere and the middle atmosphere, but may be acceptable in order to reveal the dynamical mechanism. The major uncertainty in the B04 model, however, lies in the strong assumptions that constitute a GW parameterization. Despite single-column-GW dynamics, an instantaneous response of the whole GW column to any change in the resolved flow, and the general uncertainty in the details of the dissipation mechanism (McLandress and Scinocca, 2005), GW parameterizations generally suffer from the fact that GW sources must be tuned in such a way to make the model behave reasonably. Attempts to relate the GW sources to the dynamics of the resolved scales (Charron and Manzini, 2002) may be considered as a first step to reduce the ambiguity of assumed GW sources in GW parameterizations.

GW temperature variances observed at Andøya during summer 2002 indicate that either 1) GW sources in the lower atmosphere were extraordinaryly strong or 2) propagation conditions enabled large-amplitude GWs in the MLT (Fritts et al., 2004; Rapp et al., 2004). Large energy dissipation rates and turbulence at lower altitudes than previously observed also support this hypothesis (Rapp et al., 2004; Fig. 1d). Therefore, a downward shift in the GW-driven residual circulation induced by interhemispheric coupling is probably not the full story to the observations during the MaCWAVE/MIDAS campaign. A more thorough interpretation on the basis of GCM experiments requires us to account for both the interhemispheric coupling and possible anomalies of the GW sources.

The purpose of this study is to present an expanded interpretation of the anomalous dynamics in northern summer 2002 based on more complete GCM simulations. The major difference from the model configuration used by B04 is that we now dispense with a GW parameterization and simulate GW effects explicitly. Such an attempt is not new (e.g. Hamilton et al., 1995, 1999). In accordance with arguments by Lindzen and Fox-Rabinovitz (1989), the present model configuration employs a high vertical resolution (190 hybrid levels) in order to adequately describe the propagation of GWs up to the lower thermosphere. The spectral resolution is T85. Obviously, such a model cannot in any way represent all GW scales known to be relevant in the MLT region (Fritts and Alexander, 2003). Especially high-frequency GWs are excluded. On the other hand, such a model setup can capture well the generation and propagation of inertia GWs and mid-frequency GWs, with the latter transporting sufficient momentum from low to high altitudes to account for considerable zonal-mean GW dissipation and drag in the MLT. It is likely that the resolved GW drag would occur at 

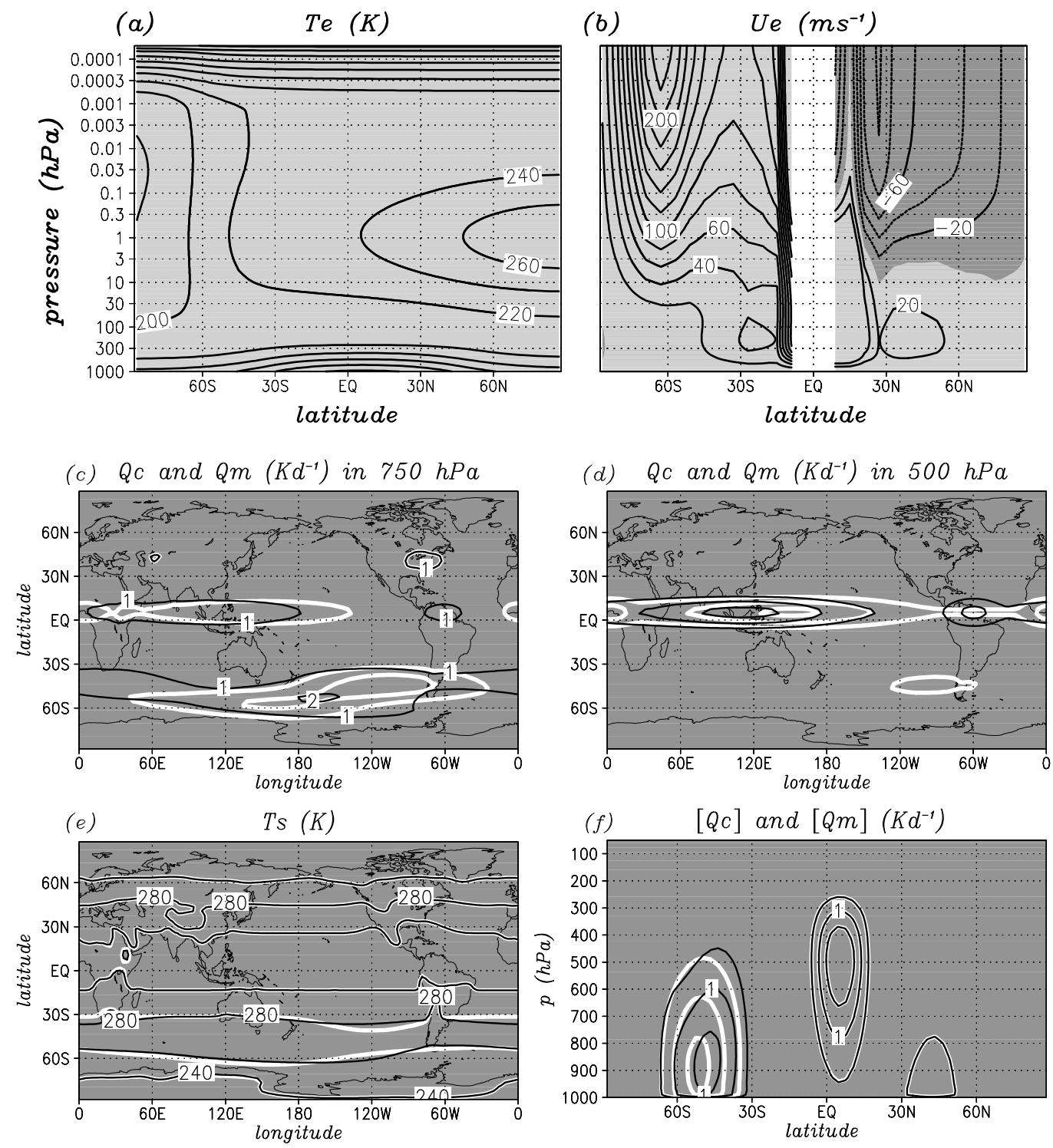

Fig. 2. Prescribed fields used for thermal forcing in the simple GCM. (a), (b) Equilibrium temperature $T_{e}$ (contour interval $20 \mathrm{~K}$ ) and corresponding thermally balanced zonal flow $U_{e}$ (contour interval $20 \mathrm{~ms}^{-1}$ ). (c), (d) Horizontal structure of the heating functions in the "normal July" run (black contours for 1, 2, $3 \mathrm{Kd}^{-1}$ ) and in the "July 2002" run (white contours for 1, 2, $3 \mathrm{Kd}^{-1}$ ) at different pressure levels. (e) Same as (c),(d), but for the surface temperature (contour interval $20 \mathrm{~K}$ ). (f) Same as (c), (d), but for the zonal means in a latitude-height cross-section (contour interval $0.5 \mathrm{Kd}^{-1}$ ).

shorter horizontal wavelengths and higher intrinsic frequencies if higher horizontal resolution was employed, and this question deserves to be addressed in the future. Nonetheless, the present model setup enables tropospheric GW sources to be simulated in a self-consistent manner, offering the opportunity to address the question raised by the findings of Fritts et al. (2004) and Rapp et al. (2004), namely whether enhanced tropospheric GW forcing may have contributed to the extraordinary dynamical state of the northern summer MLT in 2002 .
The outline of this paper is as follows. In the next section we describe those aspects of the present GCM that are of particular importance for the purpose of the present study. In Sect. 3 we compare the climatologies of the new sensitivity experiments, which were performed using essentially the same thermal forcing as in B04. Section 4 analyzes changes in the northern tropospheric GW sources that are induced by changing the latent heating functions in the southern and tropical troposphere. We briefly discuss anomalies of the temperature variations in Sect. 5. Section 6 presents results from a "transient" experiment in which we continuously 
(a) vert. mix. length $(\mathrm{km})$

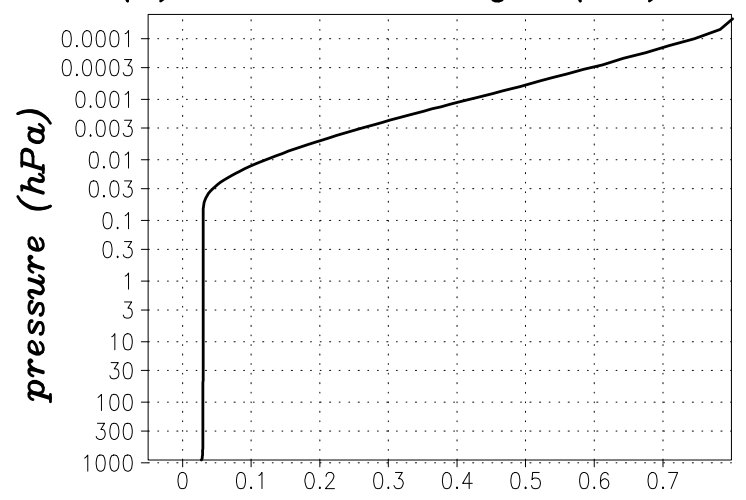

(b) horiz. mix. length $(\mathrm{km})$

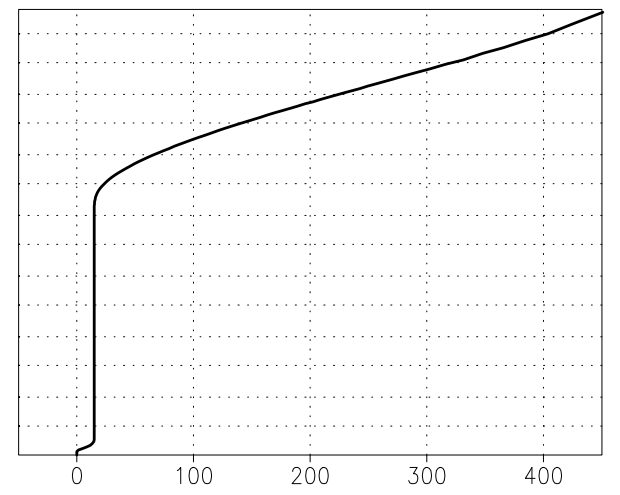

Fig. 3. Assumed vertical profiles of (a) the asymptotic vertical mixing length and (b) the horizontal mixing length.

simulate the transition from the assumed "normal July" to the "July 2002" conditions. This experiment is designed to revisit and interpret the character of the interhemispheric coupling by the summer-to-winter-pole residual circulation. In this context we also estimate the typical time scale of the interhemispheric coupling. Our results are summarized in Sect. 7.

\section{Model description}

Our model is the Kühlungsborn Mechanistic general Circulation Model (KMCM). This simple GCM has a standard spectral dynamical core. In its present setup we adopt 190 full hybrid levels from 0.1 to about $125 \mathrm{~km}$, resulting in a vertical level spacing of approximately $550 \mathrm{~m}$ from the boundary layer to $100 \mathrm{~km}$. Due to the restriction of computer resources we have run a horizontal resolution of T85 corresponding to a horizontal gridspacing of $1.4 \mathrm{deg}$ or $162 \mathrm{~km}$. We abbreviate this model version as T85/L190 model. The former lowresolution simulations presented in B04 were performed with the T31/L60 version.

We apply permanent July conditions and there is no forcing of thermal tides. The total diabatic heating in terms of sensible heat per unit mass divided by heat capacity $c_{p}$ can be written as

$$
\begin{aligned}
Q= & -\frac{T-T_{e}}{\tau}+Q_{c} \\
& +\frac{|\omega| h(-\omega)}{40 \mathrm{mb} \mathrm{d}^{-1}} Q_{m}+\text { diffusion }+ \text { frictional heating }
\end{aligned}
$$

As usual, $T$ is temperature and $T_{e}$ a zonally symmetric equilibrium temperature which is displayed in Fig. 2a. The corresponding thermally-balanced zonal mean wind is shown for reference in Fig. 2b. The relaxation time $\tau$ is 14 days in the troposphere and 7 days in the upper stratosphere and mesosphere, with an intermediate maximum of 40 days around $100 \mathrm{hPa}$. The spatial structures of the heating functions $Q_{c}$ and $Q_{m}$ are displayed in Figs. 2c, d, and f, with black contours corresponding to "normal July" conditions and white contours to "July 2002" conditions. The surface sensible heat flux is computed from a local boundary layer scheme (Holtslag and Boville, 1993) with the surface temperature (see Fig. 2e) defined as

$T_{s}=\left[T_{e}+0.4 \tau\left(Q_{c}+Q_{m}\right)\right]_{\text {surface }}$.

The differences in thermal forcing between the two model experiments are designed to induce enhanced planetary Rossby-wave activity in the Southern Hemisphere in the "July 2002" simulation. This aim is achieved by assuming almost the same heating functions for "normal July" and "July 2002" as in B04 - despite an additional self-induced heating over the continents in the northern extratropics, where the heating function $Q_{m}$ is identical in both simulations. Note that the $Q_{c}$ maximum over the maritime continent is shifted somewhat into the tropical Pacific in the "July 2002" experiment in order to account for the El Ninó in 2002. Such a procedure follows the method of Ting and Held (1990) and has turned out to be necessary for stronger planetary Rossby waves in the Southern Hemisphere in our "July 2002" simulation. Our second aim to also describe a possibly enhanced GW forcing in the northern summer troposphere for 2002 conditions is not controlled by any specified change in model forcing, but is instead allowed to respond to other shifts in local conditions such as an anomalous stationary Rossby-wave train that is induced by the modified $Q_{c}$ and ranges from the western tropical Pacific over North America to the North Atlantic (Ting and Held, 1990).

KMCM employs special parameterizations of turbulent friction. First, horizontal diffusion is included using a generalized mixing length approach in association with a symmetric stress tensor formulation appropriate for spherical coordinates (Smagorinsky, 1993; Becker, 2001). The details are 

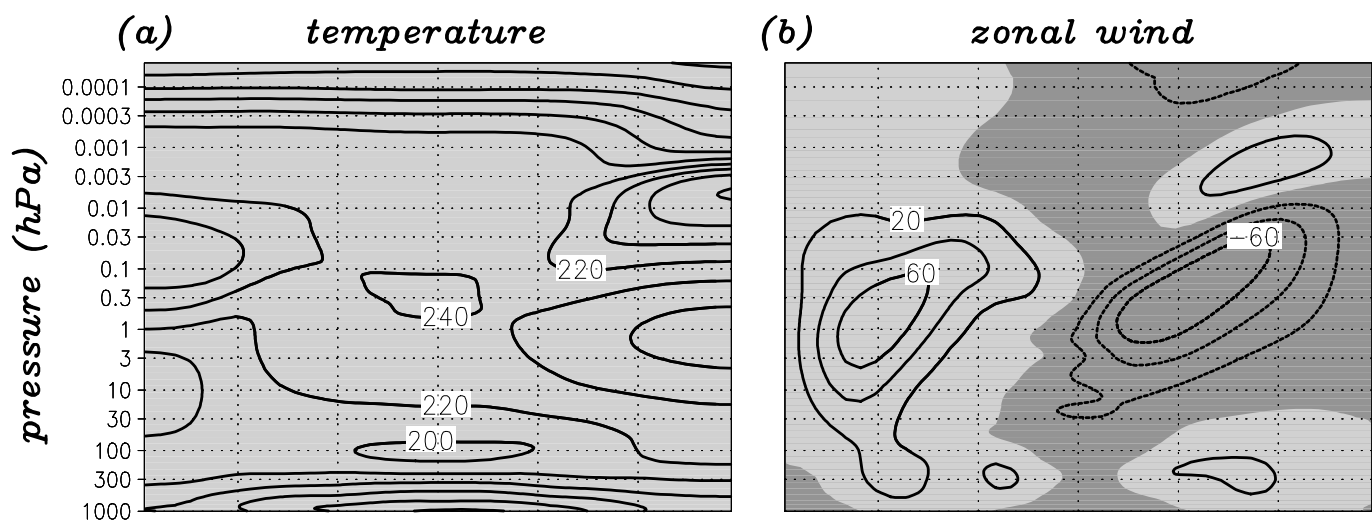

(c) merid. wind and $\Psi_{\text {res }}$

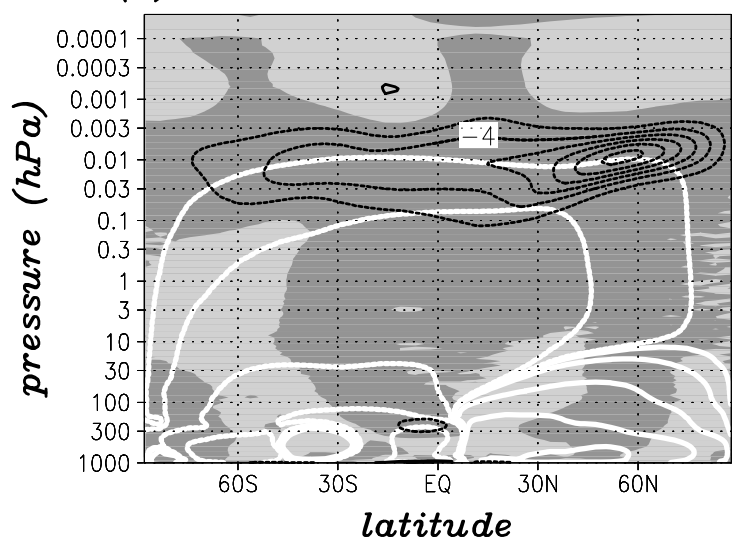

(d)

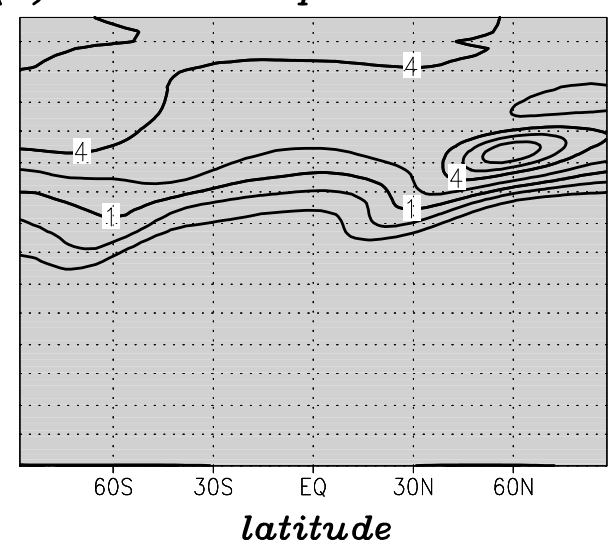

Fig. 4. Zonal-mean climatology for "July 2002" conditions. (a) Temperature (contour interval $20 \mathrm{~K}$ ). (b) Zonal wind (contour interval $20 \mathrm{~ms}^{-1}$ ). (c) Eulerian meridional wind (contour interval $2 \mathrm{~ms}^{-1}$ ). (d) Dissipation (contours $0.25,0.5,1,2,4,6,8 \mathrm{Kd}^{-1}$ ). Zero contours are not drawn. Positive and negative values are indicated by light and dark shading. The additional white contours in (c) show the residual mass streamfunction $\Psi_{\text {res }}$ (contours $\pm 0.01,0.1,1,10,100 \times 10^{9} \mathrm{kgs}^{-1}$ ).

given in Becker and Burkhardt $(2006)^{1}$. In short, the horizontal diffusion coefficient is written as $K_{h}=l_{h}^{2}|\mathrm{~S}|$, where $l_{h}$ denotes the horizontal mixing length and $\sqrt{2}|\mathrm{~S}|$ is the Frobenius norm of the strain tensor $\mathrm{S}$. This scheme is better motivated physically than conventional hyperdiffusion schemes. It also enables an efficient scale selectivity and satisfies all hydrodynamic conservation laws, including a consistent representation of the frictional heating (dissipation).

Second, the boundary-layer formulation of the vertical diffusion coefficient, which is given by the local scheme described in Holtslag and Boville (1993), is applied at all model layers, with the asymptotic vertical mixing length prescribed as a function of height. As usual, the upper boundary conditions assume zero vertical fluxes at the model lid, and conventional flux boundary conditions are applied at the bottom. The molecular diffusion coefficient diffuses momentum, but $c_{p} T$ instead of $c_{p} \Theta$ with respect to sensible heat, where $\Theta$

\footnotetext{
${ }^{1}$ Becker, E. and Burkhardt, U.: Nonlinear horizontal diffusion for GCMs. Mon. Wea. Rev., submitted, 2006.
}

is potential temperature. To calculate the frictional heating associated with vertical momentum diffusion, the finitedifferencing method of Becker (2003) is implemented, which explicitly accounts for the no-slip condition in order to ensure a closed Lorenz energy cycle in the troposphere.

Figure 3 shows the assumed profiles for the asymptotic vertical and horizontal mixing lengths. These profiles were chosen such that the resolved GWs are damped in the MLT. That is, we conceive of a dynamical-convective instability process by which the waves dissolve into smaller-scale waves and finally into turbulence, giving rise to Eliassen-Palm flux divergence that drives the mean flow. Such an assumption is supported by recent direct numerical simulations (Fritts et al., 2003, 2006), but these dynamics are not sufficiently understood for parameterization purposes at this stage. Thus, we must employ an empirical adjustment of diffusion parameters in order to ensure application of the GW drag well below the model upper boundary, as is common in middleatmosphere GCMs. Advantages of this procedure are 1) no tunable GW parameters occur in the present model and 
(a)

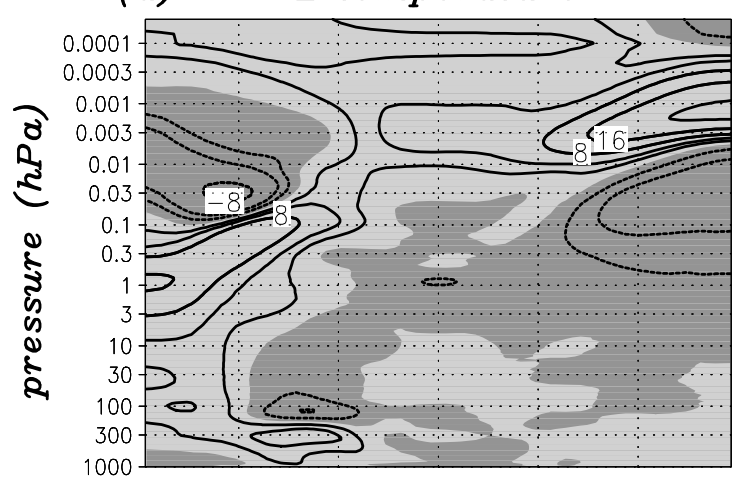

(c)

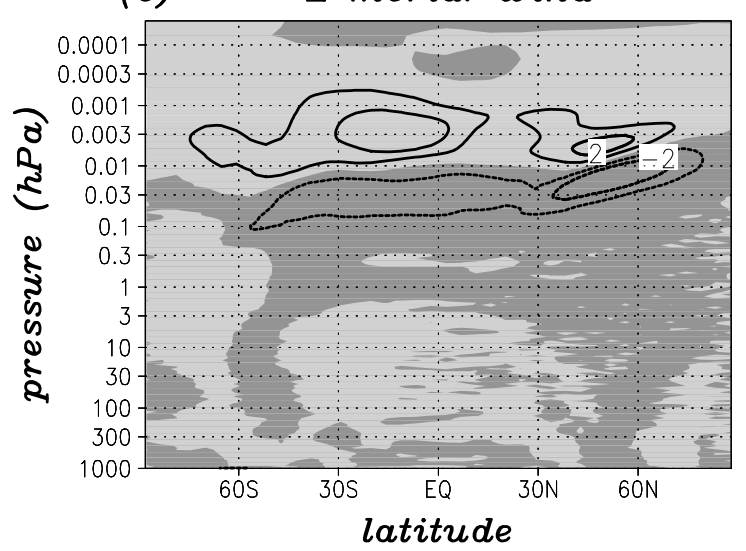

(b)

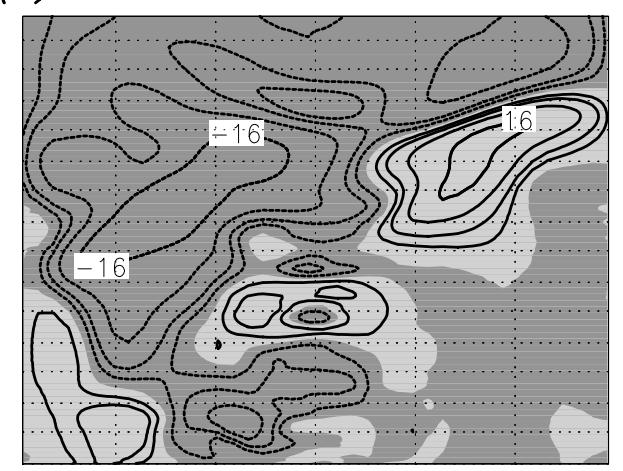

(d)

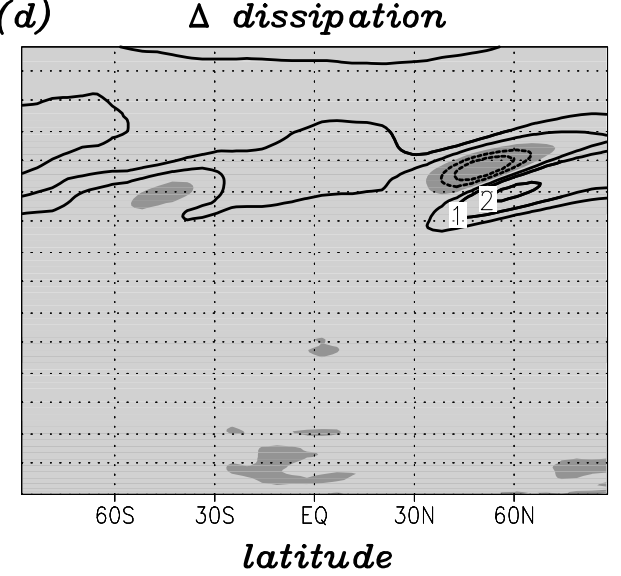

Fig. 5. Simulated zonal-mean differences in the "July 2002" simulation from the "normal July" run. (a) Temperature (contours $\pm 2,4,8,16,32 \mathrm{~K}$ ). (b) Zonal wind (contours $\pm 2,4,8,16 \mathrm{~ms}^{-1}$ ). (c) Eulerian meridional wind (contours $\pm 1,2 \mathrm{~ms}^{-1}$ ). (d) Dissipation (contours $\pm 0.5,1,2 \mathrm{Kd}^{-1}$ ). Zero contours are not drawn. Positive and negative values are indicated by light and dark shading.

2) negligible sponge-layer feedback (Shepherd et al., 1996) in our application.

The time step was $24 \mathrm{~s}$. The "normal July" and "July 2002" experiments were integrated for 200 model days in each case after equilibration of the model climatologies. Model data were sampled every $90 \mathrm{~min}$.

\section{Climatologies}

Zonal-mean fields for the "July 2002" simulation are shown in Fig. 4. The corresponding differences from the run with "normal July" conditions are displayed in Fig. 5. We will refer to such differences between the two simulations as anomalies, signals, or model response. The simulated zonalmean general circulation (Fig. 4) is reasonable. However, a few shortcomings due to dispensing with a GW parameterization should be mentioned. The resolved winter hemispheric Eliassen-Palm flux (EPF) divergence (see Appendix) is obviously too weak to account for a wind reversal in the MLT. Also, the resolved wave drag in summer (not shown) is weaker than that provided by a GW parameterization. Fur- thermore, the assumed equilibrium temperature $T_{e}$ is too warm by about $10 \mathrm{deg}$ in this region. As a result, the simulated summer mesopause is much warmer than observed. Despite these discrepancies, the simulated dissipation (frictional heating) shows the well-known summer-winter asymmetry in the MLT and is much more pronounced at high latitudes than in the T31/L60 model, with a shift to higher altitudes in summer towards the pole.

The zonal-mean model response (Fig. 5) is generally consistent with the previous sensitivity experiments (see B04, their Fig. 5). In particular, the general character of the anomalous temperatures, mean winds, and dissipation rates summarized in Fig. 1 is reproduced by the present T85/L190 model. The signals maximize at high summer latitudes, whereas the T31/L60 model version with parameterized GWs showed almost no sensitivity at high summer latitudes with respect to the meridional wind or the dissipation. That same discrepancy between the old and new simulations is also reflected in the momentum budget as discussed below.

Figures $6 a$ and $b$ show the Eliassen-Palm flux (EPF) divergence and the Coriolis force plus nonlinear advection associated with the residual circulation, loosely abbreviated as 

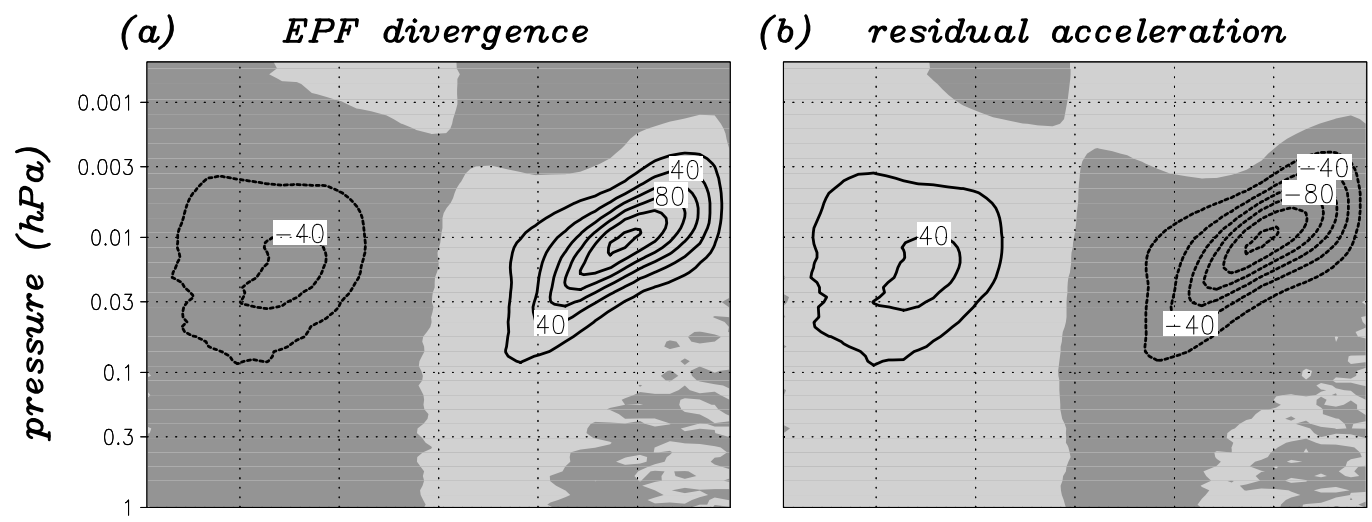

(c)

$\triangle E P F$ divergence

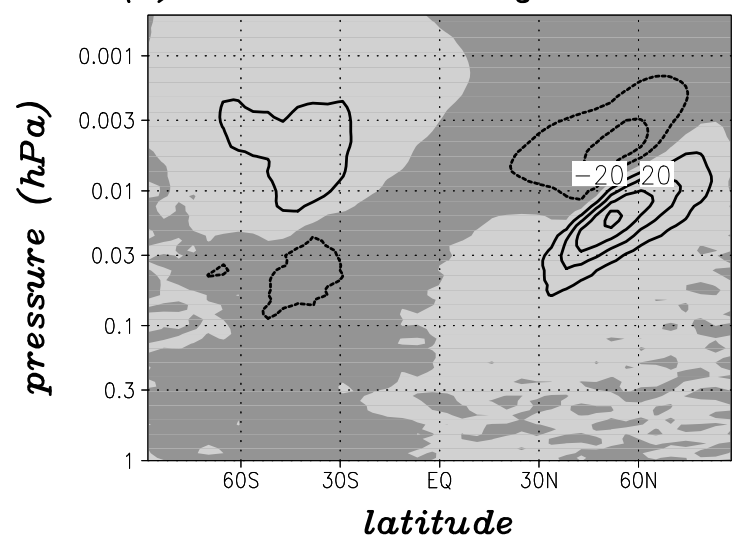

(d) $\Delta$ residual acceleration

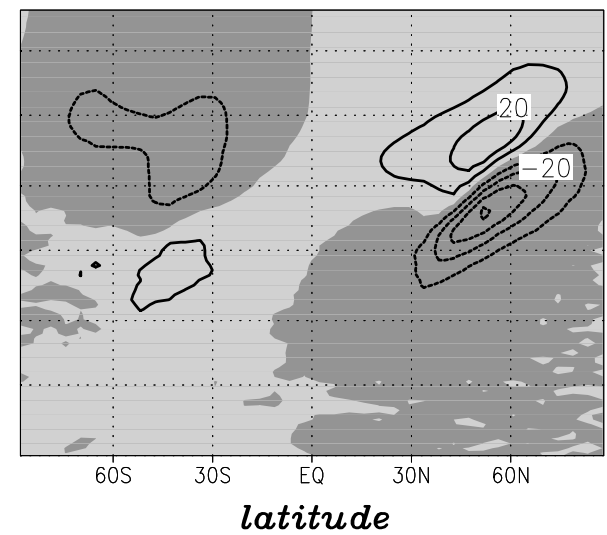

Fig. 6. Zonal-mean momentum budget in the residual picture. (a) Eliassen-Palm flux (EPF) divergence and (b) Coriolis force plus nonlinear advection associated with the residual circulation in the "July 2002" simulation (contour interval $20 \mathrm{~ms}^{-1} \mathrm{~d}^{-1}$ ). (c),(d) Same as (a), (b), but for the difference from the "normal July" run (contour interval $10 \mathrm{~ms}^{-1} \mathrm{~d}^{-1}$ ). Zero contours are not drawn. Positive and negative values are indicated by light and dark shading.

"residual acceleration", in the "July 2002" experiment. The definitions are given in the Appendix. The sum of the two terms is approximately zero, as should be the case. In particular, the frictional forces associated with our mixing-length sponge layer are negligible. Also the differences in the "July 2002" run from the "normal July" run show a satisfactory balance between the anomalous EPF divergence (Fig. 6c) and the anomalous acceleration by the residual circulation (Fig. 6d), indicating that a sponge-layer feedback (Shepherd et al., 1996) is not relevant in the present model.

Due to the enhanced planetary Rossby-wave activity, there is an anomalous deceleration in the winter stratopause region (Fig. 6c). According to Becker and Schmitz (2003), this should lead to a downward shift of the winter-hemispheric GW drag or, equivalently, to reduced deceleration at higher altitudes where the EPF divergence is dominated by the $\mathrm{GW}$ drag. This effect is indeed visible in Fig. 6c above about $0.02 \mathrm{hPa}$ in the southern winter MLT. However, the strongest signal of the anomalous EPF divergence appears in the polar summer MLT, where we can infer a highly significant downward shift of the total EPF divergence, with the anoma- lies being about one third as strong as the absolute values. In this context, we note that the resolved GW drag in the summer MLT is to a significant extent counterbalanced by the deceleration associated with travelling planetary waves which develop in situ as a result of baroclinicity (Lieberman, 1999, 2002). As a result, in each of our two simulations the maximum GW drag is about $30 \mathrm{~ms}^{-1} \mathrm{~d}^{-1}$ stronger than the maximum EPF divergence. On the other hand, the difference of the EPF divergence between both runs is quite similar to the difference of the GW drag (not shown). Since such a pronounced sensitivity of the wave driving at high summer latitudes was absent in the T31/L60 model, we expect that a stronger GW source in the lower atmosphere is essential for the anomalous wave effects in the MLT. In the following section we inspect the anomalous GW sources in more detail.

\section{Enhanced gravity-wave activity}

Figures $7 \mathrm{a}$ and $\mathrm{b}$ show the kinetic energy per unit mass associated with the transient, divergent part of the resolved 
(a)

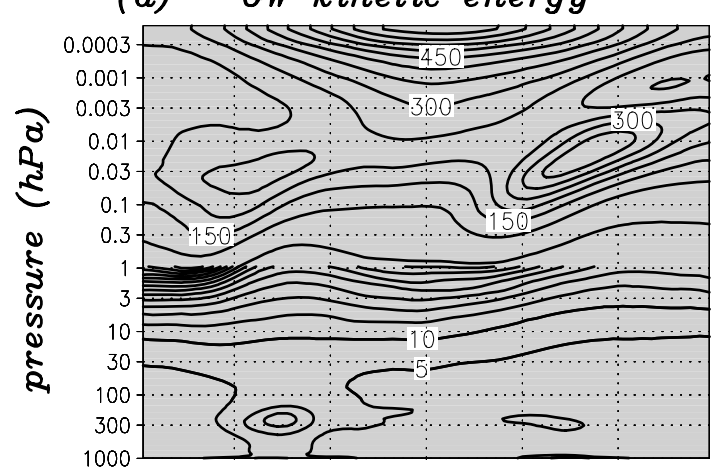

(c) $\Delta G W$ kinetic energy

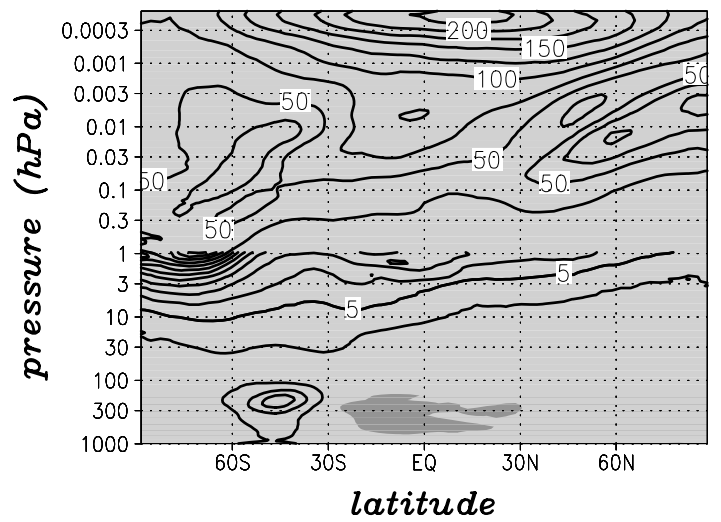

(b)

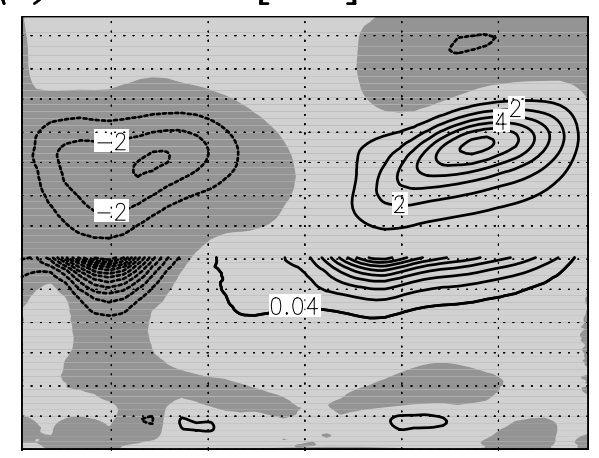

(d)

$\Delta\left[u^{*} w^{*}\right]$

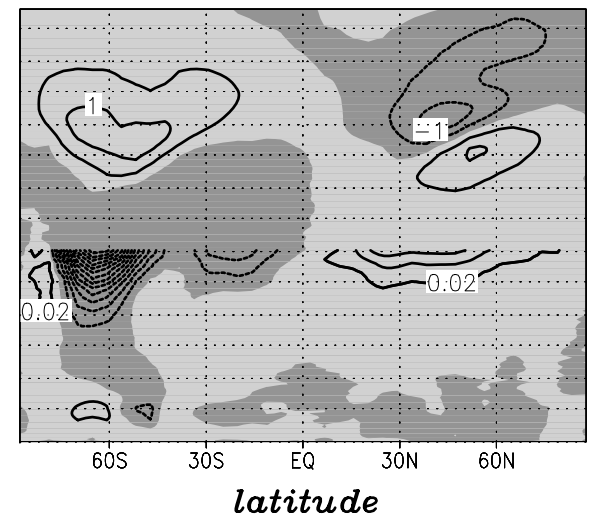

Fig. 7. GW kinetic energies and zonal-mean momentum fluxes in the climatological zonal mean. (a) Kinetic energy associated with the divergent, transient part of the resolved flow in the "July 2002" run (contour interval $50 \mathrm{~m}^{2} \mathrm{~s}^{-2}$ above $1 \mathrm{hPa}$ and $5 \mathrm{~m}^{2} \mathrm{~s}-2$ below). (b) Vertical momentum flux due to transient waves in the "July 2002" run (contour interval $1 \mathrm{~m}^{2} \mathrm{~s}^{-2}$ above $1 \mathrm{hPa}$ and $0.04 \mathrm{~m}^{2} \mathrm{~s}^{-2}$ below). (c),(d) Same as (a), (b), but for the differences in the "July 2002" experiment from the "normal July" simulation (contour intervals are 25 and $0.5 \mathrm{~m}^{2} \mathrm{~s}^{-2}$ above $1 \mathrm{hPa}$, or 2.5 and $0.02 \mathrm{~m}^{2} \mathrm{~s}^{-2}$ below). Zero contours are not drawn. Positive and negative values are indicated by light and dark shading.

flow and the vertical flux of zonal momentum associated with transient eddies in the "July 2002" experiment. Apart from synoptic-scale ageostrophic components in the troposphere and winter stratosphere, we can take these quantities as measures of the resolved GW kinetic energy and resolved GW momentum flux. Accordingly, the extratropical maxima between 0.1 and $0.003 \mathrm{hPa}$ in panels a and b mark the regions of maximum GW-mean flow interaction. Figure 7c reveals that for "July 2002" conditions the GW kinetic energy is larger everywhere in the middle atmosphere than in the "normal July" case. When we consider the $0.03 \mathrm{hPa}$ level, above which the GW drag sets in, we infer a strengthening of the GW kinetic energy by about $25 \%$ poleward of $\sim 60^{\circ} \mathrm{N}$. The corresponding increase of the GW momentum flux at polar summer latitudes is about $15 \%$. These intensifications likely contribute to the downward shifts of wave drag, meridional wind, and dissipation around $60^{\circ} \mathrm{N}$ (Figs. 6c, 5c, and $5 d)$.
The self-induced condensational heating in the Northern Hemisphere is included in the model to describe the largescale diabatic heating pattern in the northern summer troposphere as diagnosed by Wang and Ting (1999) from observational analyzes. However, even our simple parameterization for latent heating induces the generation of GWs. In fact, neglecting the summer hemispheric $Q_{m}$ results in a reduction of the mesospheric GW drag by about 50\% (not shown). In order not to prescribe any changes in GW sources in the Northern Hemisphere, the corresponding part of the heating function $Q_{m}$ is identical in all our simulations (see Fig. 2). Furthermore, we have checked that the zonally-averaged and vertically-integrated self-induced condensational heating in the Northern Hemisphere is essentially the same for both the "normal July" and the "July 2002" simulations. Nevertheless, we can diagnose an enhanced Lorenz energy cycle in the "July 2002" run, with the global-mean dissipation rate being $2.29 \mathrm{Wm}^{-2}$ compared to $1.84 \mathrm{Wm}^{-2}$ in the "normal July" run. While this globally-enhanced dissipation is due 

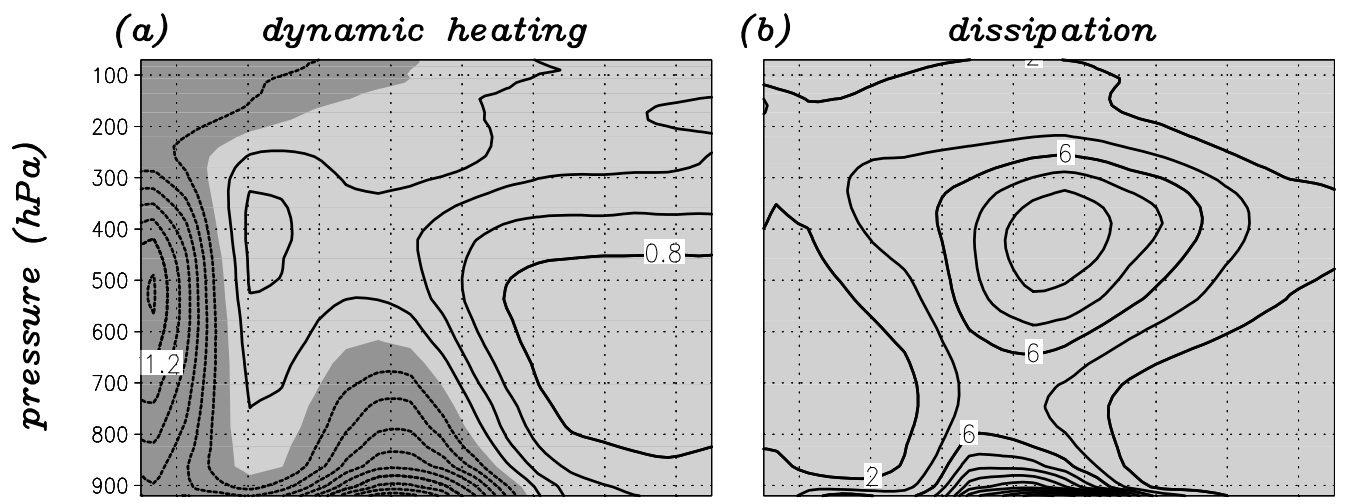

(c) $\Delta$ dynamic heating

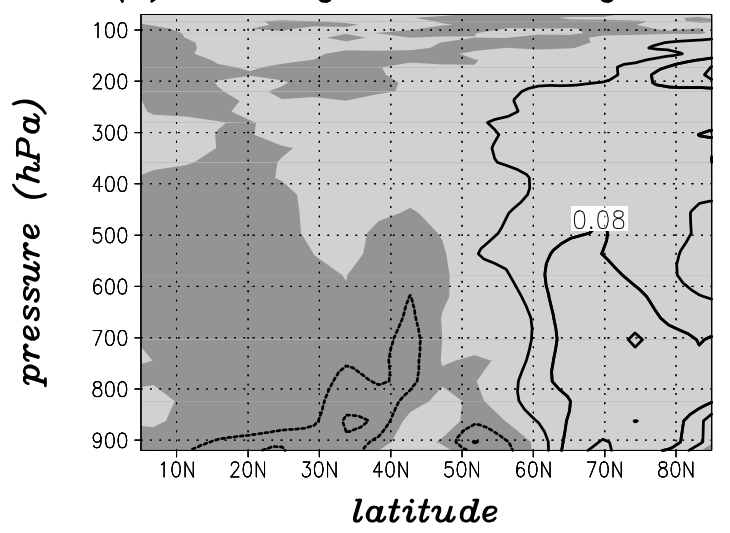

(d)

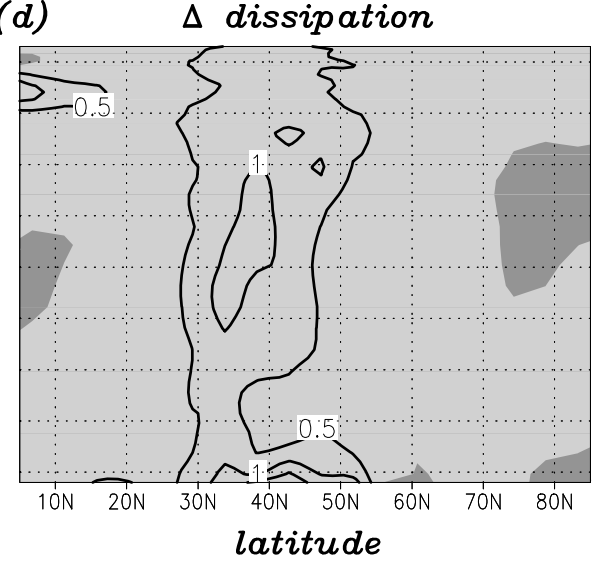

Fig. 8. (a),(b) Dynamic heating (adiabatic heating plus advection) and dissipation (frictional heating) in the northern troposphere for the "July 2002" simulation. (c), (d) Corresponding differences from the "normal July" run. Contour intervals are: (a) $0.2 \mathrm{Kd}^{-1}$, (b) $2 \times 10^{-3} \mathrm{Kd}^{-1}$, (d) $0.04 \mathrm{Kd}^{-1}$, (e) $0.5 \times 10^{-3} \mathrm{Kd}^{-1}$. Zero contours are not drawn. Positive and negative values are indicated by light and dark shading.

primarily to the modified dynamics in the southern troposphere, the northern troposphere also indicates an enhanced energy cycle. Figure 8 shows the dynamic heating, defined as adiabatic heating plus advection by the resolved flow, and the dissipation in the northern troposphere for the "July 2002" simulation, as well as the differences from the "normal July" simulation. Panel (c) clearly indicates enhanced heat transport from low to high latitudes. Furthermore, there is enhanced frictional heating in the mid-latitude troposphere (Fig. 8d), indicating enhanced dissipation of synoptic-scale wave kinetic energy in that region. We have not shown the boundary-layer dissipation below $900 \mathrm{hPa}$ in Fig. 8 since this heating is much stronger than the dissipation in the upper troposphere (Becker, 2003) and almost identical in both simulations. Summarizing, the enhanced GW activity in the northern summer hemisphere for 2002 conditions can be linked to a stronger Lorenz energy cycle in the troposphere. This sensitivity is induced primarily through imposed changes in tropical heating $Q_{c}$ and, probably to a smaller degree, by the modified winter troposphere. It is beyond the scope of this study to address the causes or the true magnitudes of these effects in greater detail, since our primary focus is on the summer MLT and we have employed a GCM unable to describe smaller-scale GWs and their energy and momentum transport explicitly.

\section{Temperature variances}

Figures $9 \mathrm{a}$ and $\mathrm{b}$ show the zonal averages of the standard deviation of temperature associated with GWs and the corresponding relative temperature variance for the model output at $70^{\circ} \mathrm{N}$, which corresponds approximately to the latitude of Andøya. We have chosen to plot zonally averaged variations instead of those at a particular longitude since longitudinal variations in GW effects in the summer MLT are less likely than in winter and the zonally averaged model response is thus more robust. The temperature variations in the simulated summer MLT are generally dominated by travelling planetary waves with zonal wavenumbers $m=1 \ldots 6$, especially the quasi-2-day wave with $m=3$. Accordingly, the simulated GW variations shown in Fig. 9 have been diagnosed by retaining only zonal wave numbers in excess of $m=10$. Observed temperature variances associated with GWs already presented by Rapp et al. (2004, their Fig. 3) are also included 

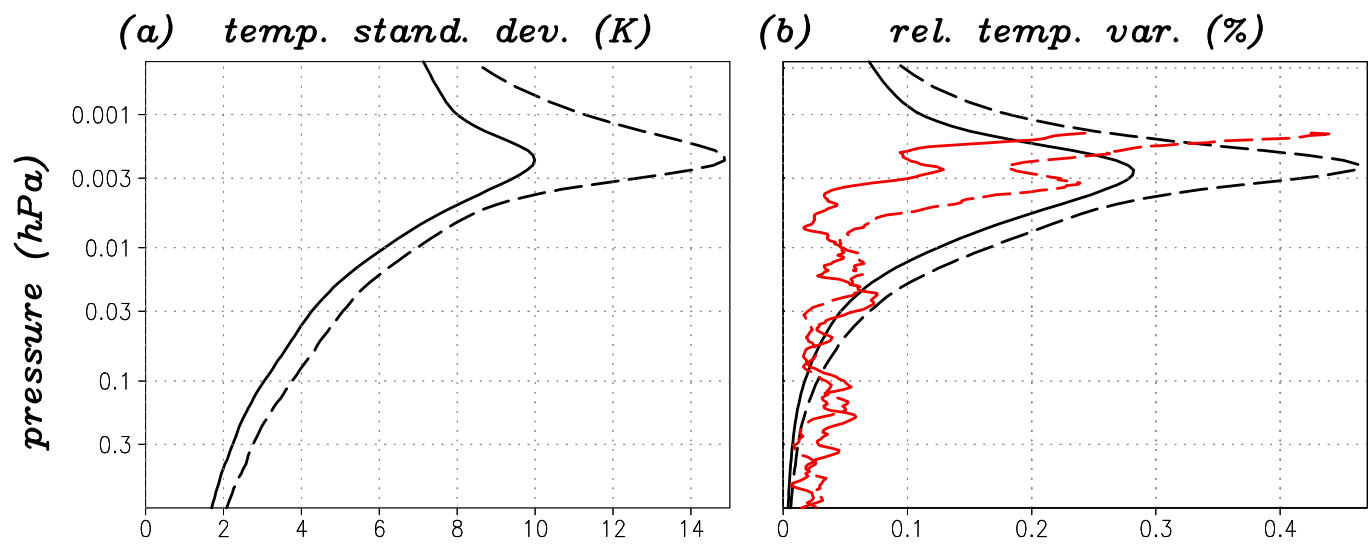

Fig. 9. (a) Zonal mean of the temperature standard deviation at $70^{\circ} \mathrm{N}$ in the "normal July" run (solid curve) and in the "July 2002 " run (dashed curve). Only zonal wavenumbers $m=11 \ldots 85$ are retained. (b) Black curves: Same as (a), but for the relative temperature variation. In addition, the red curves give observed relative temperature variations already presented by Rapp et al. (2004), which were compiled from soundings during years before 2002 (solid curve) and during the MaCWAVE year 2002 (dashed curve).

in Fig. 9b for the same altitude range (red curves). Differences between the simulated and observed temperature variations may result from insufficient spatial resolution of the model, application of adhoc assumptions in the turbulent diffusion schemes, and from uncertainties in the extraction of observed GW variations. Despite these deficiencies, the observed intensification of temperature variations is reproduced in our sensitivity experiments quite reasonably.

Rapp et al. (2004) interpreted this signal as a result of an associated increase in the background Brunt-Väisälä frequency squared, $N^{2}$, arguing that the temperature variance of a single GW scales with $N^{2}$ in regions of saturation. The complete dependence, based on the polarization relations given in Becker (2004), yields that the relative temperature variance of a saturated $\mathrm{GW}$ scales like $\overline{T^{\prime 2}} / \bar{T}^{2} \approx \overline{\Theta^{\prime 2}} / \bar{\Theta}^{2} \propto N^{2}(c-\bar{u})^{2}$, where $c$ is the phase speed and $\bar{u}$ the horizontal background wind in the direction of propagation. $^{2}$ In northern summer 2002, $N^{2}$ was indeed unusually strong due to the modified mean temperature, but at the same time $(c-\bar{u})^{2}$ should have been weaker due to the anomalous eastward wind component, provided we assume that only GWs with eastward phase speeds of the order of $30 \mathrm{~ms}^{-1}$ are relevant in the summer MLT.

The present numerical experiments clearly support enhanced GW sources as an explanation of the higher temperature variances in the MLT. However, the changes in static stability are not simulated in a satisfactory way, mainly because the absolute model temperatures are too high in the summer MLT by about 30 degrees. Therefore, the origin of the changes in temperature fluctuations cannot be addressed at present. We speculate, however, that the increases in both static stability and GW source strength likely played roles

\footnotetext{
${ }^{2}$ The remaining factors consist of constants like the horizontal wavenumber and the momentum flux at the source level.
}

in the enhanced temperature variances observed by Rapp et al. (2004) and Fritts et al. (2004) during polar summer in 2002.

\section{Interhemispheric coupling in the MLT by the residual circulation}

In the winter middle atmosphere, the downward shift of GW drag and the GW-driven branch of the residual circulation is controlled by enhanced planetary Rossby-wave activity in the stratosphere. In particular, stronger planetary Rossby waves induce a weaker and more variable eastward zonal flow, which causes the GW drag to be spread over a deeper height range and to occur on average at lower altitudes. This mechanism has proven to be valid if GW damping is defined via a saturation assumption (Becker and Schmitz, 2003). Obviously, it also applies in the present case of mixing-length based horizontal and vertical diffusion schemes (Fig. 6c). The question not answered in previous papers by Becker and Schmitz (2003) or B04 is how this signal is communicated to the summer mesosphere, where a downward shift of GW effects and the residual circulation is also found, even in the case of fixed GW sources. In particular, if we applied the same argument valid for the winter mesosphere to the summer MLT, the downshift in GW drag would suggest a reduced westward jet in the summer stratosphere and lower mesosphere, rather than stronger westward winds as seen in the previous sensitivity experiments (see B04, their Fig. 5b; Becker and Schmitz, 2003, their Fig. 3) or in falling-sphere wind soundings (Goldberg et al., 2004). Therefore, putting changes in GW sources aside, an explanation of the downward shift of the residual circulation in summer must be quite different from that for winter. In the following we propose 

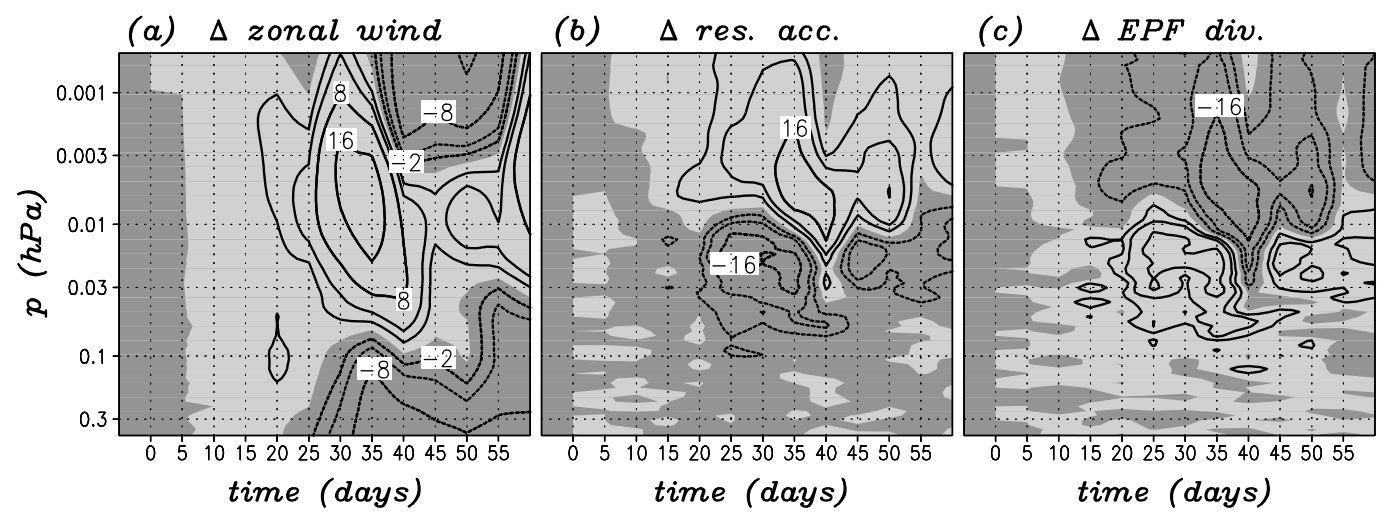

Fig. 10. Transient model response with respect to (a) zonal-mean zonal wind (contours $\pm 2,4,8,16 \mathrm{~ms}^{-1}$ ), (b) residual acceleration (contours $\pm 4,8,16 \mathrm{~ms}^{-1} \mathrm{~d}^{-1}$ ), and (c) EPF divergence (contours $\pm 4,8,16 \mathrm{~ms}^{-1} \mathrm{~d}^{-1}$ ). Each quantity is averaged over 5 days and from $15^{\circ} \mathrm{N}$ to $60^{\circ} \mathrm{N}$. Positive and negative values are indicated by light and dark shading.

an explanation for how the interhemispheric coupling in the MLT might come about.

We argue, for reasons of continuity, that a downward shift of the GW-driven branch of the winter-hemisphere residual circulation will also cause the meridional flow across the equator and in the summer hemisphere to shift to lower altitudes, with the signal decreasing towards the summer pole. This downward shift of the summer hemispheric $f v_{\text {res }}$ corresponds to a net zonal force with acceleration around the altitude of maximum GW drag and deceleration below. The resulting additional eastward wind component will cause increased vertical wavenumbers of the eastward propagating GWs, leading to GW dissipation at somewhat lower altitudes, which in turn alters the GW drag and the mean zonal flow in a way to balance the altered $f v_{\text {res }}$ and maintain steady downward control.

This transition process can be simulated in the following way. We change the latent heating functions continuously from "normal July" to "July 2002" conditions within one month, starting from some time step in the "normal July" run, defined as day 0. From day 30 on, the "July 2002" heating functions are again constant in the transient experiment. The time series of the transient run are then compared to the corresponding time series of the "normal July" integration. We monitor subsequent 5-day averages of the zonal-mean zonal wind, the residual acceleration, and the EPF divergence (see Appendix). Figure 10 shows the corresponding differences between the transition experiment and the "normal July" run, averaged between $15^{\circ}$ and $60^{\circ} \mathrm{N}$. The temporal evolution of the zonal wind signal is evident from panel (a). Note that the positive zonal wind anomaly extends well into the middle mesosphere due to the contribution from low summer latitudes (see Fig. 5b). Comparing panels a and b we see that only the upper half of the positive wind anomaly follows the anomalous residual acceleration (or $f v_{\text {res }}$ ). Hence, the transient change of the EPF divergence (or the GW drag) causes the positive wind anomaly to extend to lower altitudes than the transient change in the residual acceleration would suggest. From day 20 or so on, the transient anomalies are contaminated by the independent internal variabilities in the "normal July" and the transient experiments. In particular, the eastward GW momentum flux in the lower summer mesosphere is stronger in the transient run than in the "normal July" run around day 25, but it is weaker around day 40 (not shown). Averaging both runs from day 0 to day 60 , the transient intensification of the eastward momentum flux in the summer mesosphere turns out to be about half as strong than the climatological result presented in Fig. 7d. Thus our transient experiment cannot fully isolate the interhemispheric coupling.

Since the interhemispheric coupling occurs not only in sensitivity experiments, but also shows up as a mode of internal variability (Volodin and Schmitz, 2001), a statistical estimate of its typical time scale can be obtained from timelagged correlations in the "July 2002" simulation. The variations of the daily averaged zonal-mean temperature in the "July 2002" simulation maximize around $55^{\circ} \mathrm{S}, 0.05 \mathrm{hPa}$ and above the summer pole around $0.002 \mathrm{hPa}$ (not shown). These locations correspond to the negative and positive extrema of the temperature signal in Fig. 5a which reflect the global downshift of the summer-to-winter-pole residual circulation. We compute correlations between the time series of daily averaged zonal-mean temperatures at the two locations. The resulting correlation coefficient minimizes at -0.71 for a time lag of 28 days and it reduces to -0.14 for a 40 -day time lag, or to 0.01 for a 10 -day time lag. Hence, the typical time scale for interhemispheric coupling in the MLT due to internal variability of planetary Rossby waves in the winter hemisphere is about one month in the present model. 


\section{Summary}

We have analyzed long-term simple-GCM simulations in order to interpret various anomalous data recorded during the MaCWAVE/MIDAS measurement program at Andøya (northern Norway) during summer 2002 in the polar MLT. Our model runs have assumed permanent July conditions, one parameter set representing a typical austral winter state and another leading to enhanced planetary Rossby-wave activity to mimic conditions typical for the exceptional austral winter 2002. The novelty of the present investigation is that tropospheric GW sources and the resulting GW drag in the MLT are simulated explicitly. For this purpose, we have employed a high vertical resolution with 190 levels up to $\sim 125 \mathrm{~km}$ and a moderate spectral horizontal resolution of T85. Such a setup cannot describe all scales of GWs assumed to be important for the general circulation of the MLT. On the other hand, no ambiguous adjustment of GW sources is required, since the GW sources are self-consistently determined by the internal dynamics of the troposphere and lower stratosphere. This model feature allowed us to ask whether enhanced planetary Rossby-wave activity in the austral winter hemisphere, which we impose by adjusting our simplistic latent heating parameterizations (Sect. 2, Fig. 3), can lead to alterations of GW sources in the lower atmosphere and the resulting GW effects in the summer MLT.

The anomalous observations in northern summer 2002 were summarized in Fig. 1. They consist of lower temperatures than usual below $\sim 82 \mathrm{~km}$ and higher temperatures above, an anomalous eastward component of the zonal flow in the MLT, a downward shift of the equatorward meridional flow, and enhanced turbulent dissipation below $80 \mathrm{~km}$. Enhanced temperature fluctuations due to GW motions were also identified by Fritts et al. (2004) and Rapp et al. (2004). All these anomalies are captured reasonably by our new sensitivity experiments. Our results suggest that the observed anomalies in the high-latitude MLT during northern summer 2002 may be interpreted by a combination of two effects. First, the GW driven summer-to-winter-pole circulation was shifted to lower altitudes as a result of enhanced planetary Rossby waves in the southern winter stratosphere. We have given an extended interpretation in Sect. 6 of how this interhemispheric coupling leads to anomalous eastward zonal mean winds and higher temperatures in the summer MLT, as well as to a downward shift of GW effects. The typical time scale for this process is about one month. Second, enhanced generation of GWs occurred throughout the troposphere in association with a globally-enhanced Lorenz energy cycle, contributing to the summer MLT anomalies in the same sense as the interhemispheric coupling.

Whereas the first mechanism has proven to yield at least a qualitatively consistent interpretation of the unusual observations in 2002, the second mechanism turns out to be of particular importance at middle and high summer latitudes. Indeed, a pronounced model sensitivity shows up in the MLT around $60^{\circ} \mathrm{N}$ (Figs. 5, and 6c, and 6d), indicating that enhanced GW sources in this region are responsible for dissipation and momentum deposition at lower altitudes than usual.

\section{Appendix A}

\section{Zonal-mean momentum budget in the residual frame}

Using temperature (enthalpy) as the thermodynamic variable and pressure as the vertical coordinate, the mean meridional circulation in the residual frame is defined analogously to Andrews et al. (1987, ch. 3.5):

$v_{\text {res }}=[v]+\partial_{p} \frac{\left[T^{*} v^{*}\right]}{\frac{R}{c_{p} p}[T]-\partial_{p}[T]}$

$\omega_{\text {res }}=[\omega]-\frac{1}{\cos \phi} \partial_{y}\left(\frac{\cos \phi\left[T^{*} v^{*}\right]}{\frac{R}{c_{p} p}[T]-\partial_{p}[T]}\right)$.

Here, $v_{r e s}$ is the residual meridional wind, $\omega_{\text {res }}$ is the residual pressure velocity, and $\partial_{y}$ represents the derivative with respect to latitude $\phi$ divided by the Earth's radius. Zonal averages are indicated by brackets and deviations by asterisks. The symbols have their usual meanings otherwise. The transformed zonal momentum equation can be written as

$$
\begin{aligned}
\partial_{t}[u] & =\{\text { residual acceleration }\}+\{\text { EPF divergence }\} \\
& +\{\text { momentum diffusion }\}
\end{aligned}
$$

$\{$ residual acceleration $\}=(f+[\xi]) v_{\text {res }}-\omega_{\text {res }} \partial_{p}[u]$

$\{$ EPF divergence $\}=$

$$
\begin{aligned}
& \left.-\frac{1}{\cos ^{2} \phi} \partial_{y}\left(\cos ^{2} \phi\left[u^{*} v^{*}\right]\right)+\frac{\partial_{p}[u]\left[T^{*} v^{*}\right]}{\frac{R}{c_{p} p}[T]-\partial_{p}[T]}\right) \\
& -\partial_{p}\left(\left[u^{*} \omega^{*}\right]+\frac{(f+[\xi])\left[T^{*} v^{*}\right]}{\frac{R}{c_{p} p}[T]-\partial_{p}[T]}\right) .
\end{aligned}
$$

The GW drag is

$\{\mathrm{GW} \mathrm{drag}\}=-\partial_{p}\left[u^{*} \omega^{*}\right]$.

For steady downward control in the summer MLT, Eq. (A3) can be simplified as

$0 \approx f v_{\text {res }}+\{\mathrm{GW}$ drag $\}$.

Acknowledgements. We are indebted to P. Hoffmann, M. Rapp, and J. Russell III for helpful discussions and providing their data sets. Also the valuable comments of A. K. Smith are gratefully acknowledged. D. Fritts acknowledges research support from AFOSR under contract F49620-03-C-0045, NASA under contract NAS5-02036, and NSF under grant ATM-0137354.

Topical Editor U.-P. Hoppe thanks A. K. Smith for her help in evaluating this paper. 


\section{References}

Andrews, D. G., Holton, J. R., and Leovy, C. B.: Middle atmosphere dynamics, Academic Press, San Diego, 489, 1987.

Baldwin, M., Hirooka, T., O’Neill, A., and Yoden, S.: Major stratospheric warming in the southern hemisphere in 2002: Dynamical aspects of the ozone hole split, SPARC Newsletter, ISSN 12979961, 2003.

Becker, E.: Symmetric stress tensor formulation of horizontal momentum diffusion in global models of atmospheric circulation, $\mathrm{J}$. Atmos. Sci., 58, 269-282, 2001.

Becker, E.: Frictional heating in global climate models, Mon. Wea. Rev., 131, 508-520, 2003.

Becker, E.: Direct heating rates associated with gravity wave saturation, JASTP, 66, 683-696, 2004.

Becker, E. and Schmitz, G.: Climatological effects of orography and land-sea heating contrasts on the gravity-wave driven circulation of the mesosphere, J. Atmos. Sci., 60, 103-118, 2003.

Becker, E., Müllemann, A., Lübken, F.-J., Körnich, H., Hoffmann, P., and Rapp, M.: High Rossby-wave activity in austral winter 2002: Modulation of the general circulation of the MLT during the MaCWAVE/MIDAS northern summer program, Geophys. Res. Lett., 31, L24S03, doi:10.1029/2004GL019615, 2004.

Charron, M. and Manzini, E.: Gravity waves from fronts: Parameterization and middle atmosphere response in a general circulation model, J. Atmos. Sci., 59, 923-941, 2002.

Fritts, D. C. and Alexander, M. J.: Gravity wave dynamics and effects in the middle atmosphere, Rev. Geophys., 41, 1, doi:10.1029/2001/RG000106, 2003.

Fritts, D. C., Bizon, C., Werne, J. A., and Meyer, C. K.: Layering accompanying turbulence generation due to shear instability and gravity wave breaking, J. Geophys. Res., 108, D8, 8452, doi:10.1029/2002JD002406, 2003.

Fritts, D. C., Vadas, S. L., Wan, K., and Werne, J. A.: Mean and variable forcing of the middle atmosphere by gravity waves, J. Atmos. Solar-Terres. Phys., in press, 2006.

Fritts, D. C., Williams, B. P., She, C. Y., Vance, J. D., Rapp, M., Lübken, F.-J., Müllemann, A., Schmidlin, F. J., and Goldberg, R. A.: Observations of extreme temperature and wind gradients near the summer mesopause during the MaCWAVE/MIDAS rocket campaign, Geophys. Res. Lett., 31, L24S06, doi:10.1029/2003GL019389, 2004.

Goldberg, R. A., Fritts, D. C., Williams, B. P., Lübken, F.-J., Rapp, M., Singer, W., Latteck, R., Hoffmann, P., Müllemann, A., Baumgarten, G., Schmidlin, F. J., She, C.-Y., and Krueger, D. A.: The MaCWAVE/MIDAS rocket and groundbased measurements of polar summer dynamics: Overview and mean state structure, Geophys. Res. Lett., 31, L24S02, doi:10.1029/2004GL019411, 2004.

Goldberg, R. A., Fritts, D. C., Schmidlin, F. J., Williams, B. P., Croskey, C. L., Mitchell, J. D., Friedrich, M., Russell III, J. M., Blum, U., and Fricke, K. H.: The MaCWAVE program to study gravity wave influences on the polar mesosphere, Ann. Geophys., 24, this issue, 2006.

Hamilton, K., Wilson, R. J., Mahlman, J. D., and Umscheid, L. J.: Climatology of the SKYHI troposphere-stratospheremesosphere general circulation model, J. Atmos. Sci., 52, 5-43, 1995.

Hamilton, K., Wilson, R. J., and Hemler, R. S.: Middle atmosphere simulated with high vertical and horizontal resolution versions of a GCM: Improvements in the cold pole bias and generation of a QBO-like oscillation in the tropics, J. Atmos. Sci., 56, 38293846, 1999.

Harnik, N., Scott, R. K., and Perlwitz, J.: Wave reflection and focusing prior to the major stratospheric warming of September 2002. J. Atmos. Sci., 62, 640-650, 2005.

Holtslag, A. A. M. and Boville, B. A.: Local versus nonlocal boundary-layer diffusion in a global climate model, J. Atmos. Sci., 52, 5-43, 1993.

Körnich, H., Schmitz, G., and Becker, E.: Dependence of the annular mode in the troposphere and stratosphere on orography and land-sea heating contrasts. Geophys. Res. Lett., 30(5), 1265, doi:10.1029/2002GL016327, 2003.

Lieberman, R. S.: Eliassen-Palm fluxes of the 2-day wave, J. Atmos. Sci., 56, 2846-2861, 1999.

Lieberman, R. S.: Corrigendum, J. Atmos. Sci., 59, 2625-2627, 2002.

Lübken, F.-J., Rapp, M., and Hoffmann, P.: Neutral air turbulence and temperatures in the vicinity of polar mesosphere summer echoes, J. Geophys. Res., 107(D15), 4273, doi:10.1029/2001JD000915, 2002.

Lindzen, R. S.: Turbulence and stress owing to gravity wave and tidal breakdown, J. Geophys. Res., 86, 9707-9714, 1981.

Lindzen, R. S. and Fox-Rabinovitz, M.: Consistent vertical and horizontal resolution, Mon. Wea. Rev., 117, 2575-2583, 1989.

McLandress, Ch. and Scinocca, J. F.: The GCM response to current parameterizations of nonorographic gravity wave drag, J. Atmos. Sci., 62, 2394-2413, 2005.

Rapp, M., Strelnikov, B., Müllemann, A., Lübken, F.-J., and Fritts, D. C.: Turbulence measurements and implications for gravity wave dissipation during the MaCWAVE/MIDAS rocket program, Geophys. Res. Lett., 31, L24S07, doi:10.1029/2003GL019325, 2004.

Roscoe, H. K., Shanklin, J. D., and Colwell, S. R.: Has the Antarctic vortex split before 2002? J. Atmos. Sci., 62, 581-588, 2005.

Shepherd, T. G., Semeniuk, K., and Koshyk, J. N.: Sponge layer feedbacks in middle-atmosphere models, Geophys. Res., 101, No. D18, 23 447-23 464, 1996.

Singer, W., Lattek, R., Hoffmann, P., Williams,B., Fritts, D. C., Murayama, Y., and Sakanoi, K: Tides and planetary waves during the MaCWAVE/MIDAS summer rocket program, Geophys. Res. Lett., 32, L07S90, doi:10.1029/2004GL021607, 2005.

Smagorinsky, J.: Some historical remarks on the use of nonlinear viscosities. Large eddy simulation of complex engineering and geophysical flows, edited by: Galperin, B. and Orszag, St. A., Cambridge University Press, 3-36, 1993.

Stolarski, R. S., McPeters, R. D., and Newman, P. A.: The ozone hole of 2002 as measures by TOMS, J. Atmos. Sci., 62, 716-720, 2005.

Ting, M. and Held, I. M.: The stationary wave response to a tropical SST anomaly in an idealized GCM, J. Atmos. Sci., 47, 25462566, 1990.

Volodin, E. M. and Schmitz, G.: A troposphere-stratospheremesosphere general circulation model with parameterization of gravity waves: Climatology and sensitivity studies, Tellus, 53A, 300-316, 2001.

Wang, H. and Ting, M.: Seasonal cycle of the climatological stationary waves in the NCEP-NCAR Reanalysis, J. Atmos. Sci., 56, 3892-3919, 1999. 